\title{
How do students evaluate instructors' performance? implication of teaching abilities, physical attractiveness and psychological factors
}

\begin{abstract}
One instrument regularly seen as a basic resource in assessing pedagogical knowledge and vivid learning in different circumstances is through the method of conducting student assessment appraisal of their instructors. Nevertheless, deciding the nature of instructional abilities requires as rationale an unbiased judgment. The concern is that there are no formal techniques or formulas that would prompt accurate responses from the students. In spite of the contention surrounding students' rating on instructors, this study aims to investigate how university students in Malaysia would evaluate instructors based on non-instructional factors, such as physical attractiveness and psychological factors, which in turn may affect students' perceptions towards instructors' performance. PLS-SEM was appropriated to perform the path modelling analysis. Practical implication is discussed.
\end{abstract}

Keyword: Evaluation of instructors performance; Physical attractiveness; Teaching 